\title{
Loss of chromosome 13 material in cellular angiofibromas indicates pathogenetic similarity with spindle cell lipomas
}

\author{
Ioannis Panagopoulos ${ }^{1 *} \mathbb{D}$, Ludmila Gorunova', Bodil Bjerkehagen², Kristin Andersen', Marius Lund-Iversen² \\ and Sverre Heim ${ }^{1,3}$
}

\begin{abstract}
Background: Cellular angiofibroma is a rare benign mesenchymal neoplasm with morphological and immunohistochemical similarities to spindle cell lipoma. Karyotypic information on cellular angiofibroma is restricted to one case only which showed loss of material from chromosomes 13 and 16. A few other studies using fluorescence in situ hybridization showed deletions of the RB1 and FOXO1 loci, both of which are located in chromosome band 13q14. We present here cytogenetic data on two cellular angiofibromas with an abnormal karyotype.
\end{abstract}

Methods: G-banding and fluorescence in situ hybridization (FISH) analyses were done on two cellular angiofibromas.

Results: In both tumors, a rearrangement leading to loss of chromosome 13 material was seen, together with other structural chromosome abnormalities. FISH analysis showed heterozygous deletion of the RB1 locus (13q14) in both cases.

Conclusion: Our results demonstrate loss of chromosome 13 material in cellular angiofibroma, though not as the sole cytogenetic change, confirming the (cyto)genetic similarity of these tumors with spindle cell lipomas.

Keywords: Cellular angiofibroma, Cytogenetics, Chromosome 13, Spindle cell lipoma

\section{Background}

Cellular angiofibroma is a rare benign mesenchymal neoplasm, first described by Nucci et al. in 1997 in a series of 6 cases that occurred almost exclusively in the vulva of middle-aged women [1]. A few months later, Laskin et al. described 11 histologically similar lesions named "angiomyofibroblastoma-like" tumor, found in the inguinoscrotal area of adult men [2]. Because there were no reproducible morphologic differences between the tumors in females and males, the World Health Organization classification adopted the term "cellular angiofibroma" for this neoplasm in both genders [3]. Although cellular angiofibromas are usually found in the superficial soft tissues of the vulva and inguinoscrotal or paratesticular regions [3], the tumor has also been seen

\footnotetext{
* Correspondence: ioannis.panagopoulos@rr-research.no

${ }^{1}$ Section for Cancer Cytogenetics, Institute for Cancer Genetics and Informatics, The Norwegian Radium Hospital, Oslo University Hospital, P.O.Box 4953Nydalen, NO-0424 Oslo, Norway

Full list of author information is available at the end of the article
}

elsewhere such as the retroperitoneum, midtrunk, iliac spine, oral mucosa, knee, upper eyelid, hip, chest wall, axilla, and hypocondrium ([3, 4] and references therein). The etiology is unknown, but expression by tumor cells of estrogen and progesterone receptor suggests that these hormones play a role in tumorigenesis [3]. Cellular angiofibromas display adipose and myofibroblastic differentiation under the influence of hormones, microenvironments, cytokines, and growth factors $[1,2,5,6]$.

The tumors are smaller in women than in men [3], generally well circumscribed, and characterized by two main components: bland spindle cells and small to medium-sized vessels with mural hyalinization $[1,7,8]$. Cytogenetic information about cellular angifibroma is restricted to one case only [9] which by G-banding and fluorescence in situ hybridization (FISH) analyses was found to have the karyotype 45,XY, $\operatorname{add}(2)(\mathrm{q} 33), \operatorname{add}(12)$ (p11.2),-13[3]/44,idem,-16[2].ish add(2)(wcp13-),add(12) (wcp13+,LSI 13q14-,LSI 13q34+),der(16)(wcp13+)[3]. Because cellular angiofibroma shares morphological and 
immunohistochemical similarities with spindle cell lipoma and because monosomy for chromosomes 13 and 16 and unbalanced rearrangements of $13 \mathrm{q}$ and $16 \mathrm{q}$ are the most frequent aberrations in spindle cell lipomas, the authors suggested that cellular angiofibroma is genetically similar to spindle cell lipoma [9]. In subsequent studies, deletions of the RB1 and FOXO1 loci, located in chromosome band 13q14, were found by interphase FISH [7, 10-12].

We present here the cytogenetic data on two cases of cellular angiofibroma. Our results show consistent involvement of chromosome 13 in these tumors with loss of 13q, underscoring the suggested (cyto)genetic similarity between cellular angiofibroma and spindle cell lipomas.

\section{Methods}

\section{Patients}

Data concerning patients' gender and age, tumor location, depth, size, and immunostaining are shown in Table 1. Figure 1 shows the pathologic examination of the cellular angiofibroma of case 2 . It includes a macroscopic picture (Fig. 1a), hematoxylin and eosin (HE) staining (Fig. 1b and c), and immunoexpression of CD34 (Fig. 1d). The pathologic findings were similar in case 1. Microscopic examination of the lesions showed well demarcated tumors of spindle cells without atypia with small oval nuclei. In the background, there was a collagenous stroma with many vessels with dilated lumina of different sizes and groups of mature fatty cells. CD34 was positive at immunohistochemical analysis. The morphology was typical for a classical cellular angiofibroma.

\section{G-banding, Karyotyping, and FISH}

Fresh tissue from a representative area of the tumors was received and analyzed cytogenetically as part of our diagnostic service. The samples were disaggregated mechanically and enzymatically with collagenase II (Worthington, Freehold, NJ, USA). The resulting cells were cultured and harvested using standard techniques. Chromosome preparations were G-banded with Wright's stain (Sigma-Aldrich; St Louis, MO, USA) and examined. Metaphases were analyzed and karyograms prepared using the CytoVision computer assisted karyotyping system (Leica Biosystems, Newcastle, UK). The karyotypes were described according to the International System for Human Cytogenetics Nomenclature [13].

Interphase and metaphase FISH analyses were performed for both cases. The RB1 deletion probe, purchased from Cytocell (http://www.cytocell.co.uk), was used in order to detect deletion of the $R B 1$ locus in 13q14.2. It consists of a $318 \mathrm{~kb}$ red probe spanning the $R B 1$ gene and a 13qter green probe acting as a control for chromosome 13. Fluorescent signals were captured and analyzed using the CytoVision system from Leica Biosystems (http://www.leicabiosystems.com/pathologyimaging/cytogenetics/).

\section{Results}

Both cellular angiofibromas had abnormal karyotypes that entailed heterozygous loss of material from the long arm of chromosome 13 (Table 1, Fig. 2), together with other chromosome aberrations (Table 1). In case 1, there was an unbalanced translocation between chromosomes 1 and 13 described as $\operatorname{der}(13) \mathrm{t}(1 ; 13)(\mathrm{q} 12 \sim 21 ; \mathrm{q} 14 \sim 21)$ accompanied by monosomy 14 and aberrations of chromosome 16 (Table 1, Fig. 2a and b). FISH analysis in case 1 showed deletion of the $R B 1$ probe in 111 out of 200 investigated interphase nuclei (Fig. 2c). In case 2, an interstitial deletion in chromosome 13 was found which was described as del(13)(q12q22) together with a balanced $\mathrm{t}(10 ; 15)(\mathrm{p} 13 ; \mathrm{q} 22)$ (Table 1, Fig. 2d). FISH analysis of metaphase spreads showed that the $R B 1$ probe was heterozygously deleted also in case 2 (Fig. 2e and f).

\section{Discussion}

The present study shows consistent heterozygous loss of material from chromosome arm $13 \mathrm{q}$ in two cellular angiofibromas, supporting the observation first put forward by Hameed et al. [9] that these tumors are (cyto)genetically similar to spindle cell lipomas. The examined tumors arose in the inguinoscrotal or paratesticular region and had structural aberrations of chromosome 13

Table 1 Clinicopathological and cytogenetic data on the cellular angiofibromas

\begin{tabular}{|c|c|c|c|c|c|c|}
\hline Cases & Sex/Age & Site & Depth & Largest diameter $(\mathrm{cm})$ & Immunohistochemistry & Karyotype \\
\hline \multirow[t]{4}{*}{1} & \multirow[t]{4}{*}{ M/59 } & \multirow[t]{4}{*}{ Paratesticular } & \multirow[t]{4}{*}{ Subcutaneous } & \multirow[t]{4}{*}{5.5} & CD34 Positive & \multirow{4}{*}{$\begin{array}{l}45, X Y, \operatorname{add}(5)(\mathrm{p} 13 \sim 15),-7, \operatorname{der}(13) t(1 ; 13) \\
(\mathrm{q} 12 \sim 21 ; q 14 \sim 21),-14, \operatorname{der}(16) t(7 ; 16)(q 11 ; q 22), \operatorname{del}(18) \\
(q 21),+\operatorname{mar}[9] / 46, X Y[2]\end{array}$} \\
\hline & & & & & S100 Negative & \\
\hline & & & & & ER Negative & \\
\hline & & & & & PGR Negative & \\
\hline \multirow[t]{4}{*}{2} & \multirow[t]{4}{*}{$\mathrm{M} / 79$} & \multirow[t]{4}{*}{ Scrotum } & \multirow[t]{4}{*}{ Subcutaneous } & \multirow[t]{4}{*}{7} & CD34 Positive & \multirow[t]{4}{*}{$46, X Y, t(10 ; 15)(p 13 ; q 22), \operatorname{del}(13)(q 12 q 22)[15]$} \\
\hline & & & & & S100 Negative & \\
\hline & & & & & ER Focal positive (20\%) & \\
\hline & & & & & PGR Focal positive (10\%) & \\
\hline
\end{tabular}



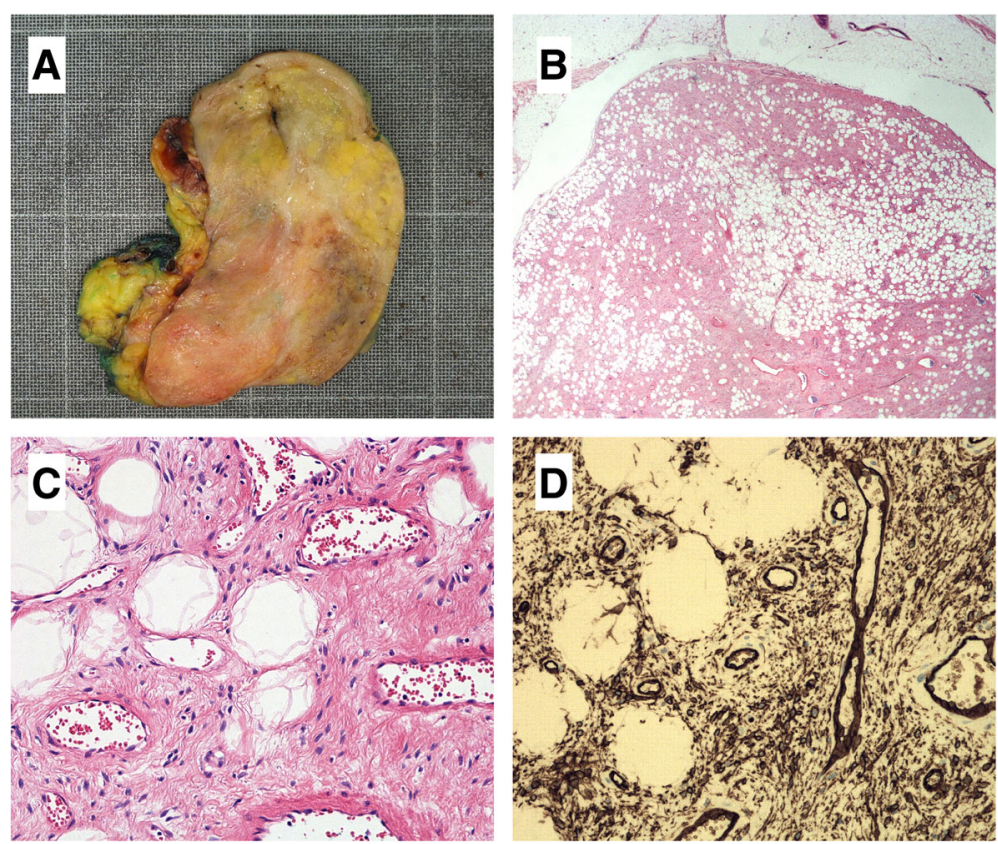

Fig. 1 Pathologic examination of the cellular angiofibroma in case 2. a Macroscopic picture of the tumor. $\mathbf{b}$ Low power HE-stained slide showing well circumscribed tumor with adipocytic components. $\mathbf{c}$ High power HE-stained slide showing spindle cells with admixed adipose tissue and blood vessels. d Immunohistochemical analysis demonstrating positivity for CD34

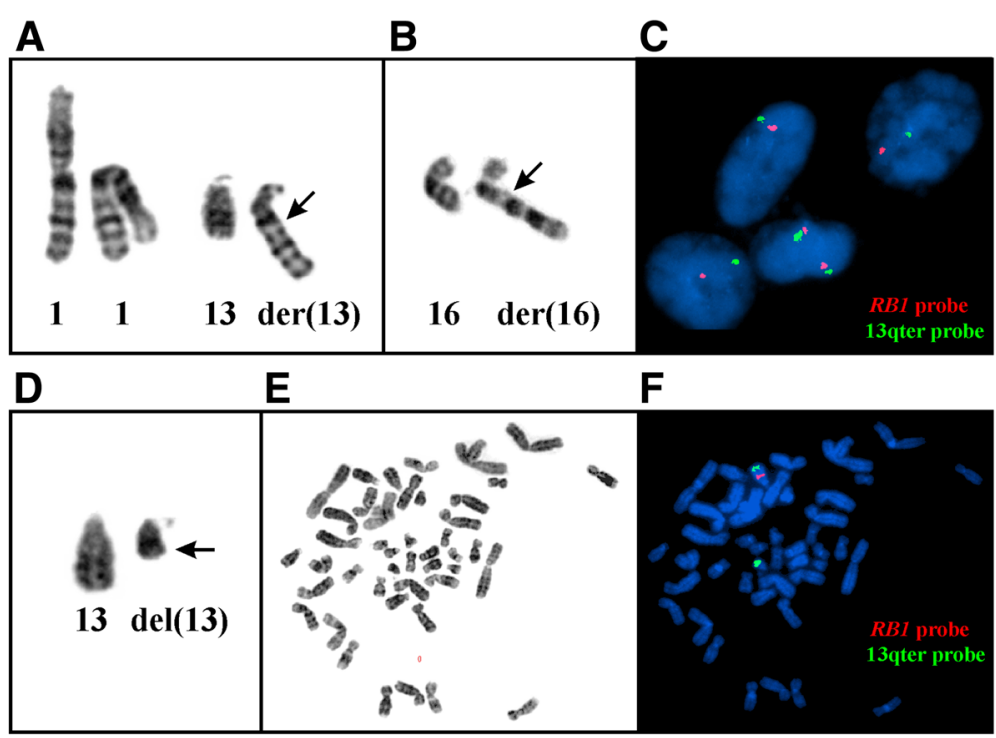

Fig. 2 G-banding and FISH information on two cellular angiofibromas. a-c: Case 1, d-f: Case 2. a Partial karyotype of case 1 showing the two normal copies of chromosome 1, a normal chromosome 13, and the der(13)t(1;13)(q12 21; $14 \sim 21)$. b Partial karyotype showing the normal chromosome 16 and the der(16)t(7;16)(q11;q22). c Interphase FISH showing one red signal (probe for the RB1 gene) and one green signal (probe for 13qter) in three interphase nuclei and two red and two green signals in one nucleus. $\mathbf{d}$ Partial karyotype of case 2 showing the normal chromosome 13 and the del(13)(q12q22). e G-banding of a metaphase spread used for FISH analysis. $\mathbf{F}$ FISH results with the RB1 deletion probe consisting of a $318 \mathrm{~kb}$ red probe spanning the RB1 gene locus and a 13qter green probe acting as a control for chromosome 13. The RB1 locus was deleted in the del(13)(q12q22). Breakpoint positions are indicated by arrows 
affecting the q12-q22 bands. In both tumors, the loss of material from chromosome 13 was accompanied by other chromosome aberrations (Table 1). Also the only hitherto karyotyped cellular angiofibroma had loss of chromosome 13 together with additional chromosome aberrations [9]. Although the analyzed G-banded cases number only three, two of which are described here (Table 1), the data show that loss of $13 \mathrm{q}$ material is not (usually) the only cytogenetic anomaly in tumors of this type (Table 1, [9]). This, too, strengthens the cytogenetic similarity with spindle cell lipomas: Most of the 28 karyotypically abnormal spindle cell lipomas reported in the cytogenetic literature had loss of material from 13q together with other chromosome abnormalities, most often loss of or from 16q (http://cgap.nci.nih.gov/ Chromosomes/Mitelman, Database last updated on August 11, 2016). Our analysis further showed that the structural aberrations affected bands 13q14 21 or 13q12-q22 which are also the most commonly lost in spindle cell lipomas [14-16]. The deletion of the RB1 locus, found by FISH, adds evidence pointing in the same direction [7, 9, 11, 12]. Maggiani et al. [11] examined by interphase FISH two cellular angiofibromas. The first tumor had a deletion of 13q14 that included the $R B 1$ and FOXO1 loci. In the second tumor, the deleted region contained FOXO1 but not RB1 [11].

Studies of spindle cell lipomas using FISH and single nucleotide polymorphism (SNP) array methodologies have identified two minimal deleted regions (MDR) in $13 q 14$ [14, 15]. In MDR1, four genes are located, including the tumor suppressor gene RB1. In MDR2, there are 34 gene loci as well as the two microRNA genes miR-15a and miR-16-1 [14]. Because the expression levels of $R B 1$ were not significantly reduced and because no mutations were seen by sequencing, the authors concluded that there is no decisive support for $R B 1$ as the main target for the 13q deletions in spindle cell lipomas [14]. Instead, their data implicate miR-16-1 as a potential target for the 13q deletions in these tumors [14]. On the other hand, immunohistochemical staining for RB1 showed that nuclear RB1 expression was deficient in all examined spindle cell lipomas, pleomorphic lipomas, and cellular angiofibromas, as well as in 17 of 19 (89\%) mammary-type myofibroblastomas [10]. At the moment, one cannot say more than that the molecular target of chromosome 13 aberrations in cellular angiofibromas remains unknown.

Although cellular angiofibroma overlaps morphologically with spindle cell lipoma and mammary-like myofibroblastoma, the three tumors also have some distinctive morphological features. In cellular angiofibroma, spindleshaped cellularity is prominent as are hyalinized blood vessels and only minimal adipose tissue. Similarly, thickwalled blood vessels are not seen in the other two entities.
In spindle cell lipomas, a mixture of mature adipocytes and bland spindle cells are found against a mucinous, myxoid, or fibrous background. In mammary-type myofibroblastoma, finally, fascicles of spindle cells with features of myofibroblasts are seen, with intervening hyalinized collagenous stroma together with various amounts of adipose tissue ([11, 12, 17] and references therein). The morphologic similarities of these tumors together with their cytogenetic similarities, in particular loss of material from the long arm of chromosome 13, suggest that they arise through largely identical pathogenetic mechanisms from a common stromal precursor cell which then undergoes (myo)fibroblastic or adipocyte differentiation [11, 17].

\section{Conclusions}

Our results show consistent involvement of chromosome 13 in cellular angiofibromas with loss of 13q, underscoring the suggested (cyto)genetic similarity between cellular angiofibroma and spindle cell lipomas.

\section{Abbreviations \\ FISH: Fluorescence in situ hybridization; HE: Hematoxylin and eosin; \\ MDR: Minimal deleted region; SNP: Single nucleotide polymorphism}

\section{Acknowledgments}

We thank Dr. Lobmaier for critical reading of the manuscript.

\section{Funding}

This work was supported by grants from the Norwegian Radium Hospital Foundation.

\section{Availability of data and materials}

All available data are included in the manuscript and its figures.

\section{Authors' contributions}

IP designed the research, evaluated the cytogenetics and FISH data, and wrote the manuscript. LG performed cytogenetics and FISH experiments and interpreted the data. BB made the pathologic evaluations. KA performed cytogenetics and FISH experiments and interpreted the data. ML-I made the pathologic evaluations. SH supervised the project, evaluated the cytogenetics and FISH data, and wrote the manuscript. All authors read and approved the final version on the manuscript.

\section{Competing interests}

The authors declare that they have no competing interests.

\section{Consent for publication}

Written informed consent was obtained from the patients to publication of the case details. The ethics committee's approval included a review of the consent procedure. A copy of the consent form is available on request for review by the Editor of this journal.

\section{Ethics approval and consent participate}

The study was approved by the regional ethics committee (Regional komité for medisinsk forskningsetikk Sør-Øst, Norge, http://helseforskning.etikkom.no, REC no S-07474a), and written informed consent was obtained from the patients to publication of the case details. The ethics committee's approval included a review of the consent procedure. All patient information has been de-identified.

\section{Author details}

${ }^{1}$ Section for Cancer Cytogenetics, Institute for Cancer Genetics and Informatics, The Norwegian Radium Hospital, Oslo University Hospital, P.O.Box 4953Nydalen, NO-0424 Oslo, Norway. ${ }^{2}$ Department of Pathology, The Norwegian Radium Hospital, Oslo University Hospital, Oslo, Norway. ${ }^{3}$ Faculty of Medicine, University of Oslo, Oslo, Norway. 
Received: 11 November 2016 Accepted: 31 January 2017

\section{Published online: 13 February 2017}

\section{References}

1. Nucci MR, Granter SR, Fletcher CD. Cellular angiofibroma: a benign neoplasm distinct from angiomyofibroblastoma and spindle cell lipoma. Am J Surg Pathol. 1997;21:636-44.

2. Laskin WB, Fetsch JF, Mostofi FK. Angiomyofibroblastomalike tumor of the male genital tract: analysis of 11 cases with comparison to female angiomyofibroblastoma and spindle cell lipoma. Am J Surg Pathol. 1998;22:6-16.

3. Fletcher CDM, Flucke U, Iwasa Y. Cellular angiofibroma. In: Fletcher CDM, Bridge JA, Hogendoorn PCW, Mertens F, editors. World health organization classification of tumours. Pathology and genetics of tumours of soft tissue and bone. Lyon: IARC Press; 2013. p. 65-6.

4. Mandato VD, Santagni S, Cavazza A, Aguzzoli L, Abrate M, La Sala GB. Cellular angiofibroma in women: a review of the literature. Diagn Pathol. 2015;10:114. doi:10.1186/s13000-015-0361-6.

5. Micheletti AM, Silva AC, Nascimento AG, Da Silva CS, Murta EF, Adad SJ. Cellular angiofibroma of the vulva: case report with clinicopathological and immunohistochemistry study. Sao Paulo Med J. 2005;123:250-2. doi:/S151631802005000500010

6. Khmou M, Lamalmi N, Malihy A, Rouas L, Alhamany Z. Cellular angiofibroma of the vulva: a poorly known entity, a case report and literature review. BMC Clin Pathol. 2016;16:8. doi:10.1186/s12907-016-0030-z.

7. Flucke U, van Krieken JH, Mentzel T. Cellular angiofibroma: analysis of 25 cases emphasizing its relationship to spindle cell lipoma and mammary-type myofibroblastoma. Mod Pathol. 2011;24:82-9. doi:10.1038/modpathol.2010.170.

8. Iwasa Y, Fletcher CD. Cellular angiofibroma: clinicopathologic and immunohistochemical analysis of 51 cases. Am J Surg Pathol. 2004;28:1426-35.

9. Hameed M, Clarke K, Amer HZ, Mahmet K, Aisner S. Cellular angiofibroma is genetically similar to spindle cell lipoma: a case report. Cancer Genet Cytogenet. 2007;177:131-4. doi:10.1016/j.cancergencyto.2007.05.016.

10. Chen BJ, Marino-Enriquez A, Fletcher CD, Hornick JL. Loss of retinoblastoma protein expression in spindle cell/pleomorphic lipomas and cytogenetically related tumors: an immunohistochemical study with diagnostic implications. Am J Surg Pathol. 2012;36:1119-28. doi:10.1097/PAS. Ob013e31825d532d.

11. Maggiani F, Debiec-Rychter M, Vanbockrijck M, Sciot R. Cellular angiofibroma: another mesenchymal tumour with 13q14 involvement, suggesting a link with spindle cell lipoma and (extra)-mammary myofibroblastoma. Histopathology. 2007:51:410-2. doi:10.1111/j.1365-2559.2007.02775.x.

12. Wyn I, Debiec-Rychter M, Van Cleynenbreugel B, Sciot R. Cellular angiofibroma of the prostate: a rare tumor in an unusual location. Case Rep Pathol. 2014;2014:871530. doi:10.1155/2014/871530.

13. Schaffer LG, McGowan-Jordan J, Schmid M. ISCN 2013: An International System for Human Cytogenetic Nomenclature. Basel: Karger; 2013. Place.

14. Bartuma H, Nord KH, Macchia G, Isaksson M, Nilsson J, Domanski HA, Mandahl N, Mertens F. Gene expression and single nucleotide polymorphism array analyses of spindle cell lipomas and conventional lipomas with 13q14 deletion. Genes Chromosomes Cancer. 2011;50:619-32. doi:10.1002/gcc.20884.

15. Dahlén A, Debiec-Rychter M, Pedeutour F, Domanski HA, Höglund M, Bauer HC, Rydholm A, Sciot R, Mandahl N, Mertens F. Clustering of deletions on chromosome 13 in benign and low-malignant lipomatous tumors. Int J Cancer. 2003;103:616-23. doi:10.1002/ijc.10864.

16. Dal Cin P, Sciot R, Polito P, Stas M, de Wever I, Cornelis A, Van den Berghe $\mathrm{H}$. Lesions of $13 q$ may occur independently of deletion of $16 q$ in spindle cell/pleomorphic lipomas. Histopathology. 1997;31:222-5.

17. Maggiani F, Debiec-Rychter M, Verbeeck G, Sciot R. Extramammary myofibroblastoma is genetically related to spindle cell lipoma. Virchows Arch. 2006;449:244-7. doi:10.1007/s00428-006-0228-z.

\section{Submit your next manuscript to BioMed Central and we will help you at every step:}

- We accept pre-submission inquiries

- Our selector tool helps you to find the most relevant journal

- We provide round the clock customer support

- Convenient online submission

- Thorough peer review

- Inclusion in PubMed and all major indexing services

- Maximum visibility for your research

Submit your manuscript at www.biomedcentral.com/submit
) Biomed Central 